OPEN ACCESS

Edited by:

Massimo Libra

University of Catania, Italy

Reviewed by:

Luca Arcaini,

University of Pavia, Italy

Francesco Passamonti,

University of Insubria, Italy

${ }^{*}$ Correspondence:

Hongwei S

sihw@163.com

Jianzhong Cao

caolv2000@163.com

†These authors have contributed equally to this work

Specialty section:

This article was submitted to Hematologic Malignancies,

a section of the journal

Frontiers in Oncology

Received: 09 December 2019

Accepted: 04 May 2020

Published: 19 June 2020

Citation:

Yao N, Hou Q, Zhang S, Xiao H, Liang Y, Xu X, Guo R, Li H, Lan S, Si H and Cao J (2020) Prognostic Nutritional Index, Another Prognostic

Factor for Extranodal Natural Killer/T Cell Lymphoma, Nasal Type. Front. Oncol. 10:877. doi: 10.3389/fonc.2020.00877

\section{Prognostic Nutritional Index, Another Prognostic Factor for Extranodal Natural Killer/T Cell Lymphoma, Nasal Type}

\begin{abstract}
Ningning Yao ${ }^{1 \dagger}$, Qing Hou ${ }^{1 \dagger}$, Shuangping Zhang ${ }^{2 \dagger}$, Huan Xiao ${ }^{3}, \mathrm{Yu} \mathrm{Liang}^{4}$, Xiaokai Xu ${ }^{3}$, Ruyuan Guo ${ }^{4}$, Hongwei $\mathrm{Li}^{4}$, Shengmin Lan ${ }^{4}$, Hongwei Si ${ }^{3 *}$ and Jianzhong Cao ${ }^{1,4 *}$

${ }^{1}$ Department of Radiobiology, Shanxi Provincial Cancer Hospital, Taiyuan, China, ${ }^{2}$ Department of Surgery, Shanxi Provincial Cancer Hospital, Taiyuan, China, ${ }^{3}$ Department of Nuclear Medicine, The First Affiliated Hospital of Anhui Medical University, Hefei, China, ${ }^{4}$ Department of Radiotherapy, Shanxi Provincial Cancer Hospital, Taiyuan, China
\end{abstract}

Objective: The prognostic nutritional index (PNI) is a significant prognostic factor in diffuse large B cell lymphoma, follicular lymphoma, and other malignancies. The current study aimed to explore its prognostic role in extranodal natural killer/T cell lymphoma (ENKTL).

Methods: Patients diagnosed with ENKTL and treated during 2002 and $2018(n=184)$ were retrospectively recruited. PNI was calculated from albumin concentration $(\mathrm{g} / \mathrm{L})$ and total lymphocyte count $\left(* 10^{9} / \mathrm{L}\right)$. The association of PNI and overall survival (OS) or progression-free survival (PFS) was assessed in univariate analysis and multivariate Cox regression validated by the 10-fold cross-validation method.

Results: Survival analyses showed that both OS and PFS differed significantly between PNI groups stratified by a cutoff value of 49.0. The 3- and 5-year OS were 42.5 and $36.3 \%$ in the low-PNI $(\mathrm{PNI}<49)$ subgroup and $70.6 \%$ and $63.9 \%(P<0.001)$ in the high-PNI (PNI $\geq 49$ ) subgroup, respectively. The corresponding PFS showed a similar pattern (38.4, 32.4 vs. $64.8,54.0 \%, P<0.001)$. Multivariate analysis indicated that PNI was significantly independent for both $\mathrm{OS}(\mathrm{HR}=0.517,95 \% \mathrm{Cl}=0.322-0.831, P=0.006)$ and PFS $(\mathrm{HR}=0.579,95 \% \mathrm{Cl}=0.373-0.899, P=0.015)$. Furthermore, integrating PNI into the models of IPI (International Prognostic Index), KPI (Korean Prognostic Index), and PINK (prognostic index of natural killer lymphoma) could improve the area under the curve (AUC) and reduce the integrated Brier score (IBS) and Akaike Information Criterion (AIC) value of each model.

Conclusion: PNI was a significant prognostic indicator for ENKTL.

Keywords: extranodal natural killer/T cell lymphoma, nasal type, prognostic nutritional index, lymphocyte, albumin, prognosis

\section{INTRODUCTION}

As a rare non-Hodgkin's lymphoma, extranodal natural killer/T cell lymphoma, nasal type (ENKTL) is closely associated with Epstein-Barr virus infection and relatively prevalent in Asia and South America $(1,2)$. Although the patients' prognosis has been obviously improved by new drugs and radiotherapy techniques $(3,4)$, some of them are still frequently relapsed. 
Previous studies indicated the compromised prognostic role of international prognostic index (IPI) in ENKTL compared to other aggressive non-Hodgkin's lymphomas $(5,6)$. Therefore, the Korean Prognostic Index (KPI) was proposed, and its prognostic power could be further improved by integrating some laboratory results (7-10). After that, other predictors were explored, such as regional lymph node involvement, primary tumor invasion, hemoglobin level, and others (11-13).

It was reported that the progression of cancer was strongly associated with inflammation and nutritional status (14). Although the molecular mechanism was still unclear, many nutrition and inflammatory factors were related to the prognosis of cancer patients $(9,15,16)$. The prognostic nutritional index (PNI), calculated from serum albumin (17) and absolute peripheral lymphocyte count (18), is an integrated factor for both nutritional status and systemic inflammation. It was a prognostic marker for some malignancies, including diffuse large B cell lymphoma and follicular lymphoma (19-21). Therefore, in this study, we tried to evaluate its prognostic ability among ENKTL patients.

\section{MATERIALS AND METHODS}

\section{Patients and Method}

From Jan 2002 to Dec 2018, ENKTL (nasal type) patients were retrospectively retrieved from the documents at the Shanxi Provincial Cancer Hospital. The inclusion criteria were as follows: (a) pathologically proved ENKTL according to the WHO Classification of Tumors of Haematopoietic and Lymphoid Tissues, (b) no anti-tumor treatment before diagnosis, (c) with follow-up $>1$ month. Patients with upper and nonupper aerodigestive tract NK/T-cell lymphoma (UADT and nonUADT) were stratified according to the previous studies (22). Primary tumor invasion (PTI) was assessed according to the published criteria (23). The followed prognostic factors included those in the models of IPI (24), KPI (5), PIT (25), and PINK (26), and sex, laboratory measurements, etc. The study was approved by the ethics committees at the Shanxi Provincial Cancer Hospital, and the review board approved to waive the requirement for informed consent.

\section{Laboratory Measurements}

Blood cells and serum albumin level were quantified by the Sysmex XE-5000 fully automated hematological analyzer (Japan) and the Hitachi 7600 automatic biochemical analyzer (Japan), respectively. The reports included white blood cell (WBC), neutrophil, monocyte, lymphocyte, and platelet count, hemoglobin, and serum albumin levels. PNI was calculated by Equation (1) (27).

$$
\mathrm{PNI}=\operatorname{albumin}(\mathrm{g} / \mathrm{L})+5 \times \text { lymphocyte count }\left({ }^{*} 10^{9} / \mathrm{L}\right)
$$

\section{Statistical Analysis}

The optimal cutoff value for stratifying PNI was determined by the change point method from Contal and O'Quigley (SurvMisc package, R project, version 3.6.1) (28). The potentially confounded factors between the high- and low-PNI groups were balanced by the propensity score matching (PSM) method with a ratio of $1: 1$ and a caliper width of 0.5 (Matchit package, $\mathrm{R}$ project, version 3.6.1) (29). The matched factors included treatment modalities, age, sex, ECOG score, Ann Arbor Stage, B symptoms, LDH level, regional lymph node involvement, subtype, and extranodal sites of involvement. Between the matched PNI stratifications, patient characteristics were in Supplementary Table 1, and the univariate and multivariate analysis against OS/PFS were performed.

Overall survival (OS) was defined from the date of diagnosis to death from any reasons. Progression-free survival (PFS) was measured from the date of diagnosis to the first relapse, progression, or death. The survival differences between the stratifications of prognostic factors were analyzed by the KaplanMeier method and log-rank test, and the effect of risk factors on survival was analyzed by the univariate and multivariate Cox proportional hazards regression $(P<0.05)$. The regression was confirmed by the 10 -fold cross-validation method (30) and was evaluated by the indices of AUC and integrated Brier score (IBS), respectively. IBS is an index of prediction error, and a lower value indicates better accuracy. Akaike Information Criterion (AIC) analysis was also performed to compare the discriminative abilities of different models, and a predictive model with a low smaller AIC value indicates a better model fit.

\section{RESULTS}

\section{Patient Characteristics}

Patient characteristics are listed in Table $\mathbf{1}(n=184)$. The median age of the patients is 46 years (range: $9-81$ years). In this cohort of patients, the optimal cutoff value of PNI was determined by the change point method and was comparable to that in the previous study (49 vs. 45) (31). The low- and high-PNI stratifications had diverse baseline characteristic distributions in ECOG, LDH level, hemoglobin, neutrophil, lymphocytes, and white blood cell count, and received significant treatment strategies. Characteristics of the patients matched by the PSM method are listed in Supplementary Table 1. Except KPI $(P=$ 0.046), almost all the variables are well-balanced between the PNI stratifications.

\section{Treatment Strategy}

The enrolled patients were treated by radiotherapy alone ( $n=$ $15)$, chemotherapy alone $(n=61)$, chemotherapy followed by radiotherapy $(n=83)$, radiotherapy followed by chemotherapy $(n=11)$, and concurrent radio-chemotherapy $(n=14)$. Initial chemotherapy regimens were CHOP or CHOP-like $(n=39)$, L-Asparaginase (L-Asp) $(n=83)$, gemcitabine $(n=28)$, and others $(n=19)$. The treatment modalities and chemotherapy regimens were not significantly different between the PNI stratifications (Table 1).

\section{Survival}

The median survival time of the patients was 82.4 months, and 82 patients $(44.6 \%)$ died during the period of follow-up. The $3-$ and 5-year OS were 56.3 and 50.1\%, and 3- and 5-year PFS were 52.1 and $42.9 \%$, respectively. The significant factors of OS or PFS 
TABLE 1 | Comparison of patient characteristics between the PNI stratifications.

\begin{tabular}{|c|c|c|c|c|}
\hline \multirow[t]{2}{*}{ Characteristics } & \multirow{2}{*}{$\begin{array}{c}\text { All } \\
\text { No. (\%) }\end{array}$} & \multirow{2}{*}{$\begin{array}{c}\text { PNI }<49 \\
\text { No. (\%) }\end{array}$} & \multirow{2}{*}{$\begin{array}{c}\mathrm{PNI} \geq 49 \\
\text { No. (\%) }\end{array}$} & \multirow[t]{2}{*}{$P$} \\
\hline & & & & \\
\hline Age & $148(80.4)$ & 72 (75.8) & $76(85.4)$ & 0.101 \\
\hline \multicolumn{5}{|l|}{$\leq 60$ years } \\
\hline$>60$ years & 36 (19.6) & $23(24.2)$ & $13(14.6)$ & \\
\hline \multicolumn{5}{|l|}{ Sex } \\
\hline Male & $145(78.8)$ & $70(73.7)$ & $75(84.3)$ & 0.079 \\
\hline Female & $39(21.2)$ & $25(26.3)$ & $14(15.7)$ & \\
\hline \multicolumn{5}{|l|}{ ECOG score } \\
\hline $0-1$ & 147 (79.9) & $70(73.7)$ & 77 (86.5) & 0.030 \\
\hline$\geq 2$ & $37(20.1)$ & 25 (26.3) & $12(13.5)$ & \\
\hline \multicolumn{5}{|l|}{ LDH level } \\
\hline$\leq 245 \mathrm{U} / \mathrm{L}$ & $130(70.7)$ & $60(63.2)$ & $70(78.7)$ & 0.021 \\
\hline$>245 \mathrm{U} / \mathrm{L}$ & 54 (29.3) & $35(36.8)$ & 19 (21.3) & \\
\hline \multicolumn{5}{|l|}{ B symptoms } \\
\hline No & 117 (63.6) & $55(57.9)$ & $62(69.7)$ & 0.097 \\
\hline Yes & $67(36.4)$ & $40(42.1)$ & $27(30.3)$ & \\
\hline \multicolumn{5}{|c|}{ No. of extranodal sites } \\
\hline$<2$ & $159(86.4)$ & $78(82.1)$ & $81(91.0)$ & 0.078 \\
\hline$\geq 2$ & $25(13.6)$ & $17(17.9)$ & $8(9.0)$ & \\
\hline \multicolumn{5}{|l|}{ Ann Arbor Stage } \\
\hline$|-| \mid$ & $142(77.2)$ & $68(71.6)$ & $74(83.1)$ & 0.062 \\
\hline III-IV & $42(22.8)$ & $27(28.4)$ & 15 (16.9) & \\
\hline \multicolumn{5}{|l|}{ Primary site } \\
\hline UADT & $170(92.4)$ & $88(92.6)$ & $82(92.1)$ & 0.899 \\
\hline Non-UADT & $14(7.6)$ & $7(7.4)$ & $7(7.9)$ & \\
\hline \multicolumn{5}{|l|}{ PTI } \\
\hline Absent & $118(64.1)$ & $56(58.9)$ & $62(69.7)$ & 0.130 \\
\hline Present & $66(35.9)$ & $39(41.1)$ & 27 (30.3) & \\
\hline \multicolumn{5}{|l|}{ KPI score } \\
\hline $0-1$ & 117 (63.6) & $50(52.6)$ & 67 (75.3) & 0.001 \\
\hline $2-4$ & $67(36.4)$ & $45(47.4)$ & $22(24.7)$ & \\
\hline \multicolumn{5}{|l|}{ PIT score } \\
\hline $0-1$ & $154(83.7)$ & $72(75.8)$ & $82(92.1)$ & 0.003 \\
\hline $2-4$ & 30 (16.3) & 23 (24.2) & $7(7.9)$ & \\
\hline \multicolumn{5}{|l|}{ IPI score } \\
\hline $0-1$ & 133 (72.3) & 61 (64.2) & 72 (80.9) & 0.011 \\
\hline $2-5$ & $51(27.7)$ & $34(35.8)$ & $17(19.1)$ & \\
\hline \multicolumn{5}{|l|}{ PINK score } \\
\hline 0 & $100(54.3)$ & $45(47.4)$ & $55(61.8)$ & 0.139 \\
\hline$\geq 1$ & $84(45.7)$ & $50(52.7)$ & 34 (38.2) & \\
\hline \multicolumn{5}{|l|}{ Leukocyte } \\
\hline$\leq 1.5 \times 10^{9} / \mathrm{L}$ & $86(46.7)$ & $71(74.7)$ & 15 (16.9) & $<0.001$ \\
\hline$>1.5 \times 10^{9} / \mathrm{L}$ & 98 (53.3) & $24(25.3)$ & 74 (83.1) & \\
\hline \multicolumn{5}{|l|}{ Neutrophil } \\
\hline$\leq 3.0 \times 10^{9} / \mathrm{L}$ & $83(45.1)$ & $56(58.9)$ & 27 (30.3) & $<0.001$ \\
\hline$>3.0 \times 10^{9} / \mathrm{L}$ & $101(54.9)$ & $39(41.4)$ & $62(69.7)$ & \\
\hline \multicolumn{5}{|l|}{ Platelet } \\
\hline$\leq 200 \times 10^{9} / \mathrm{L}$ & 71 (38.6) & $40(42.1)$ & $31(34.8)$ & 0.311 \\
\hline$>200 \times 10^{9} / \mathrm{L}$ & $113(61.4)$ & 55 (57.9) & $58(65.2)$ & \\
\hline
\end{tabular}

(Continued)
TABLE 1 | Continued

\begin{tabular}{|c|c|c|c|c|}
\hline \multirow[t]{2}{*}{ Characteristics } & All & PNI $<49$ & $\mathrm{PNI} \geq 49$ & \multirow[t]{2}{*}{$P$} \\
\hline & No. (\%) & No. (\%) & No. (\%) & \\
\hline \multicolumn{5}{|l|}{ White cell } \\
\hline$\leq 5.0 \times 10^{9} / \mathrm{L}$ & $88(47.8)$ & $64(67.4)$ & $24(27.0)$ & $<0.001$ \\
\hline$>5.0 \times 10^{9} / \mathrm{L}$ & $96(52.2)$ & 31 (32.6) & 65 (73.0) & \\
\hline \multicolumn{5}{|l|}{ Hemoglobin } \\
\hline$\leq 120 \mathrm{~g} / \mathrm{L}$ & 44 (23.9) & $33(34.7)$ & $11(12.4)$ & $<0.001$ \\
\hline$>120 \mathrm{~g} / \mathrm{L}$ & $140(76.1)$ & 62 (65.3) & 78 (87.6) & \\
\hline \multicolumn{5}{|l|}{ Treatment } \\
\hline RT alone & $15(8.2)$ & $8(8.4)$ & $7(7.9)$ & 0.097 \\
\hline CT alone & $61(33.1)$ & $38(40.0)$ & 23 (25.8) & \\
\hline CRT & $108(58.7)$ & 49 (51.6) & $59(66.3)$ & \\
\hline \multicolumn{5}{|l|}{ CT regimen } \\
\hline L-Asp-based & $83(49.1)$ & 45 (51.7) & 38 (46.3) & 0.539 \\
\hline Other & 86 (50.9) & 42 (48.3) & $44(53.7)$ & \\
\hline
\end{tabular}

UADT, upper aerodigestive tract NKVT-cell lymphoma; PTI, primary tumor invasion; KPI, Korean Prognostic Index; IPI, International Prognostic Index; PINK, Prognostic index of natural killer lymphoma; $L D H$, lactate dehydrogenase; RT, radiotherapy; $C T$, chemotherapy; CRT, chemoradiotherapy; L-Asp, L-asparaginase.

with univariate survival analysis are listed in Table 2 . The highPNI group had higher 5-year OS (63.9 vs. $36.3 \%$; $P<0.001$ ) and PFS (54.0 vs. $32.4 \% ; P<0.001)$ than the low-PNI group (Figures 1A,B).

The multivariate survival analysis validated by the 10 fold cross method indicated that PNI was an independently prognostic predictor for both OS ( $\mathrm{HR}=0.517,95 \% \mathrm{CI}=0.322$ $0.831, P=0.006)$ and PFS ( $\mathrm{HR}=0.579,95 \% \mathrm{CI}=0.373-$ $0.899, P=0.015)$. The prognostic effect of significant factors with multivariate analysis (PNI, ECOG score, serum LDH level, radiotherapy, and L-Asp-based chemotherapy) was demonstrated by the forest plot (Figure 2).

In the univariate and multivariate analysis of the PSM patients (Supplementary Table 2), PNI was also significantly against OS $(\mathrm{HR}=0.522,95 \% \mathrm{CI}=0.318-0.858, P=0.010)$ and PFS (HR $=0.609,95 \% \mathrm{CI}=0.385-0.963, P=0.034)$. The adjusted 5 year OS and PFS were 77.8 and $62.9 \%$ in the high-PNI group and were 54.3 and $40.7 \%$ in the low-PNI group (Figures 1C,D), respectively. In the Cox regression validated by the 10 -fold cross method, the factors PNI, ECOG, PIT score, and L-Asp-based chemotherapy were significant for both OS and PFS. Above all, whether PSM is balanced or not, PNI was a significant factor for the prognosis of the patients.

\section{PNI Under L-Asp-Based Chemotherapy}

In this study, 83 patients were treated with L-Asp-based chemotherapy with/without RT. Among these patients, the 3and 5 -year OS $(n=45)$ were 54.3 and $45.9 \%$ in the low-PNI group and were 77.8 and $77.8 \%$ in the high-PNI group $(n=38$; Figure 3A), respectively. Similar results were also found in PFS (Figure 3B). The multivariate analysis indicated that PNI was also significantly against $\mathrm{OS}(\mathrm{HR}=0.327,95 \% \mathrm{CI}=0.137-0.782$, 
TABLE 2 | Univariate survival analysis of the enrolled patients.

\begin{tabular}{|c|c|c|c|c|c|c|c|}
\hline \multirow[t]{2}{*}{ Factors } & & \multicolumn{2}{|c|}{ OS (\%) } & \multirow[t]{2}{*}{$P$} & \multicolumn{2}{|c|}{ PFS (\%) } & \multirow[t]{2}{*}{$P$} \\
\hline & & 3 years & 5 years & & 3 years & 5 years & \\
\hline \multirow[t]{2}{*}{ Age } & $\leq 60$ years & 58.8 & 53.6 & 0.032 & 53.6 & 45.7 & 0.132 \\
\hline & >60 years & 45.8 & 35.5 & & 46.0 & 31.5 & \\
\hline \multirow[t]{2}{*}{ Sex } & Male & 58.0 & 51.7 & 0.441 & 52.8 & 45.2 & 0.382 \\
\hline & Female & 49.6 & 44.7 & & 49.9 & 30.4 & \\
\hline \multirow[t]{2}{*}{ ECOG score } & $0-1$ & 64.6 & 57.8 & $<0.001$ & 60.9 & 49.5 & $<0.001$ \\
\hline & $\geq 2$ & 25.9 & 22.2 & & 18.5 & 18.5 & \\
\hline \multirow[t]{2}{*}{ LDH level } & $\leq 245 \mathrm{U} / \mathrm{L}$ & 60.4 & 57.9 & 0.002 & 56.0 & 48.6 & 0.013 \\
\hline & $>245 \mathrm{U} / \mathrm{L}$ & 46.8 & 25.7 & & 36.8 & 26.8 & \\
\hline \multirow[t]{2}{*}{ B symptoms } & No & 54.6 & 48.6 & 0.669 & 51.9 & 41.5 & 0.980 \\
\hline & Yes & 59.7 & 52.9 & & 52.7 & 45.5 & \\
\hline \multirow[t]{2}{*}{ No. of extranodal sites } & $<2$ & 58.8 & 52.0 & 0.077 & 54.2 & 44.0 & 0.158 \\
\hline & $\geq 2$ & 38.9 & 38.9 & & 39.1 & 39.1 & \\
\hline \multirow[t]{2}{*}{ Ann Arbor Stage } & $|-| \mid$ & 59.4 & 52.0 & 0.245 & 53.9 & 43.2 & 0.561 \\
\hline & III-IV & 44.6 & 44.6 & & 45.3 & 45.3 & \\
\hline \multirow[t]{2}{*}{ Primary site } & UADT & 56.2 & 49.6 & 0.541 & 51.6 & 43.8 & 0.787 \\
\hline & Non-UADT & 58.0 & 58.0 & & 58.0 & 21.8 & \\
\hline \multirow[t]{2}{*}{ Regional lymph node involvement } & No & 63.0 & 55.3 & 0.004 & 57.6 & 47.5 & 0.008 \\
\hline & Yes & 31.3 & 31.3 & & 27.6 & 27.6 & \\
\hline \multirow[t]{2}{*}{ PNI } & $\mathrm{PNI}<49$ & 42.5 & 36.3 & $<0.001$ & 38.4 & 32.4 & 0.001 \\
\hline & $P N I \geq 49$ & 70.6 & 63.9 & & 66.3 & 54.0 & \\
\hline \multirow[t]{2}{*}{ KPI score } & $0-1$ & 61.9 & 56.8 & 0.012 & 57.6 & 47.7 & 0.029 \\
\hline & $2-4$ & 45.7 & 35.2 & & 41.5 & 33.7 & \\
\hline \multirow[t]{2}{*}{ PIT score } & $0-1$ & 62.1 & 56.8 & $<0.001$ & 57.7 & 48.1 & $<0.001$ \\
\hline & $2-5$ & 27.4 & 27.4 & & 24.1 & 24.1 & \\
\hline \multirow[t]{2}{*}{ IPI score } & $0-1$ & 62.5 & 56.8 & 0.001 & 57.5 & 47.3 & 0.011 \\
\hline & $2-5$ & 39.3 & 28.0 & & 37.1 & 29.7 & \\
\hline \multirow[t]{2}{*}{ PINK score } & 0 & 63.5 & 56.5 & 0.014 & 55.9 & 47.5 & 0.097 \\
\hline & $\geq 1$ & 46.7 & 41.2 & & 44.8 & 36.1 & \\
\hline \multirow[t]{2}{*}{ Leukocytopenia } & $\leq 1.5 \times 10^{9} / L$ & 45.4 & 36.6 & 0.002 & 41.0 & 32.2 & 0.002 \\
\hline & $>1.5 \times 10^{9} / \mathrm{L}$ & 65.7 & 61.0 & & 61.7 & 51.9 & \\
\hline \multirow[t]{2}{*}{ Neutropenia } & $\leq 3.0 \times 10^{9} / \mathrm{L}$ & 50.4 & 40.1 & 0.092 & 45.0 & 33.8 & 0.115 \\
\hline & $>3.0 \times 10^{9} / \mathrm{L}$ & 61.3 & 58.1 & & 57.9 & 49.9 & \\
\hline \multirow[t]{2}{*}{ Platelets } & $\leq 200 \times 10^{9} / \mathrm{L}$ & 47.7 & 45.6 & 0.240 & 44.9 & 42.8 & 0.416 \\
\hline & $>200 \times 10^{9} / \mathrm{L}$ & 61.9 & 52.7 & & 56.6 & 42.1 & \\
\hline \multirow[t]{2}{*}{ White cell count } & $\leq 5.0 \times 10^{9} / \mathrm{L}$ & 50.5 & 46.5 & 0.189 & 45.7 & 40.8 & 0.194 \\
\hline & $>5.0 \times 10^{9} / \mathrm{L}$ & 61.5 & 53.6 & & 56.5 & 45.2 & \\
\hline Hemoglobin & $\leq 120 \mathrm{~g} / \mathrm{L}$ & 47.4 & 41.0 & 0.136 & 45.5 & 27.1 & 0.138 \\
\hline & $>120 \mathrm{~g} / \mathrm{L}$ & 59.3 & 53.4 & & 54.3 & 47.3 & \\
\hline $\mathrm{RT}$ & Yes & 63.1 & 56.1 & 0.005 & 58.5 & 50.3 & 0.002 \\
\hline & No & 42.8 & 38.1 & & 39.1 & 28.5 & \\
\hline L-Asp-based CT & Yes & 65.1 & 61.0 & 0.004 & 61.2 & 51.1 & 0.009 \\
\hline & No & 49.1 & 42.0 & & 44.7 & 36.0 & \\
\hline
\end{tabular}

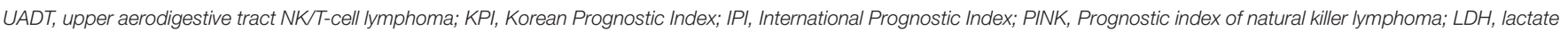
dehydrogenase; $R T$, radiotherapy; $L-A s p, L$-asparaginase; $C T$, chemotherapy.

$P=0.012)$ and PFS (HR $=0.461,95 \% \mathrm{CI}=0.221-0.961$, $P=0.039$; Supplementary Table 3).

\section{Prognostic Power of PNI}

To evaluate the prognostic power of PNI in ENKTL patients, we separately integrate PNI into the model of IPI, KPI, and PINK, which are defined in Supplementary Table 4. Figure 4A demonstrates that after integrating PNI, the area under the curve (AUC) of all models could be improved from 4 to $8 \%$, and the results are confirmed by the time-dependent AUC (Figure 4B). Furthermore, IBS values of IPI, KPI, and PINK could be decreased from 0.190 

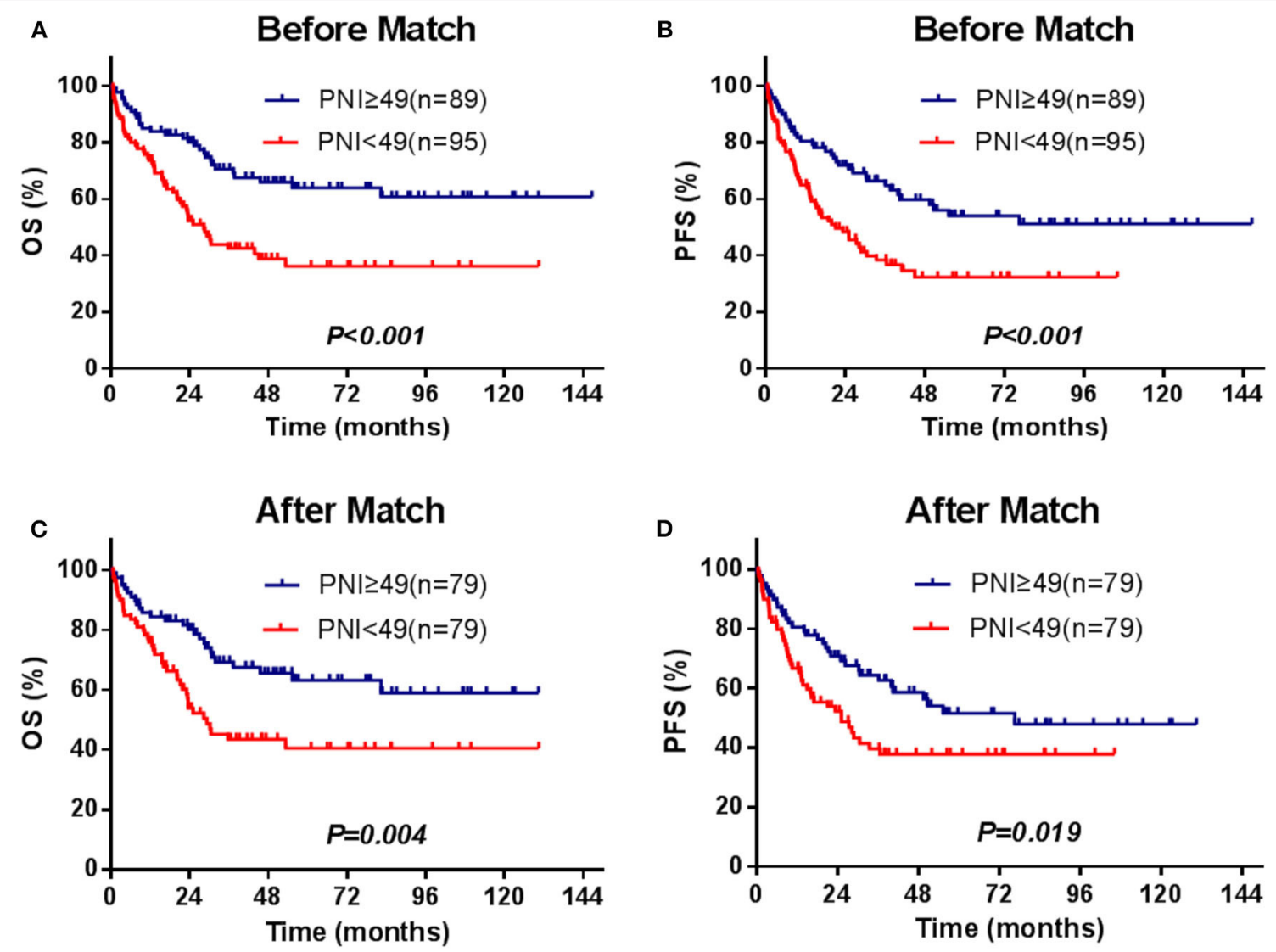

FIGURE 1 | Survival curves for the PNI stratifications $(\geq 49,<49)$, OS, and PFS for the enrolled patients $(\mathbf{A}, \mathbf{B})$ and for those[[Inline Image]] matched by the PSM method (C,D)

\begin{tabular}{|c|c|c|c|c|c|c|}
\hline Variables & OS & $\mathrm{HR}(95 \% \mathrm{Cl})$ & $P$ & PFS & $\mathrm{HR}(95 \% \mathrm{Cl})$ & $P$ \\
\hline \multicolumn{7}{|l|}{$\overline{\text { ECOG }}$} \\
\hline$\geq 2$ vs. $0-1$ & & $2.605(1.590-4.269)$ & $<0.001$ & & $2.670(1.651-4.318)$ & $<0.001$ \\
\hline \multicolumn{7}{|l|}{ LDH } \\
\hline$>245 u / l$ vs. $\leq 245 u / l$ & & $1.995(1.260-3.160)$ & 0.003 & & $1.703(1.097-2.644)$ & 0.018 \\
\hline \multicolumn{7}{|l|}{ PNI } \\
\hline$\geq 49$ vs. $<49$ & & $0.517(0.322-0.831)$ & 0.006 & $\mathrm{i}$ & $0.579(0.373-0.899)$ & 0.015 \\
\hline \multicolumn{7}{|l|}{ RT } \\
\hline yes vs. no & it & $0.628(0.398-0.993)$ & 0.046 & -i & $0.634(0.412-0.977)$ & 0.039 \\
\hline \multicolumn{7}{|l|}{ L-Asp-based CT } \\
\hline yes vs. no & $\begin{array}{ll} & -4 \\
\vdots & \\
0 & 1\end{array}$ & $0.473(0.296-0.757)$ & 0.002 & 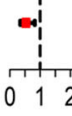 & $0.534(0.347-0.822)$ & 0.004 \\
\hline
\end{tabular}

FIGURE 2 | Forest plots of multivariate analysis. PNI is as an independently prognostic factor for OS and PFS.

to 0.183 , from 0.196 to 0.191 , and from 0.203 to 0.194 (Supplementary Figure 1). The AIC value of the models were also decreased from 776.46 to 770.29 , from 783.73 to 779.72 , and from 787.41 to 780.56 , respectively. Therefore, integrating
PNI into current prognostic models could improve AUC, reduce estimation error (as indicated by IBS), and showed better predictive abilities (as indicated by a low AIC value) in this cohort. 

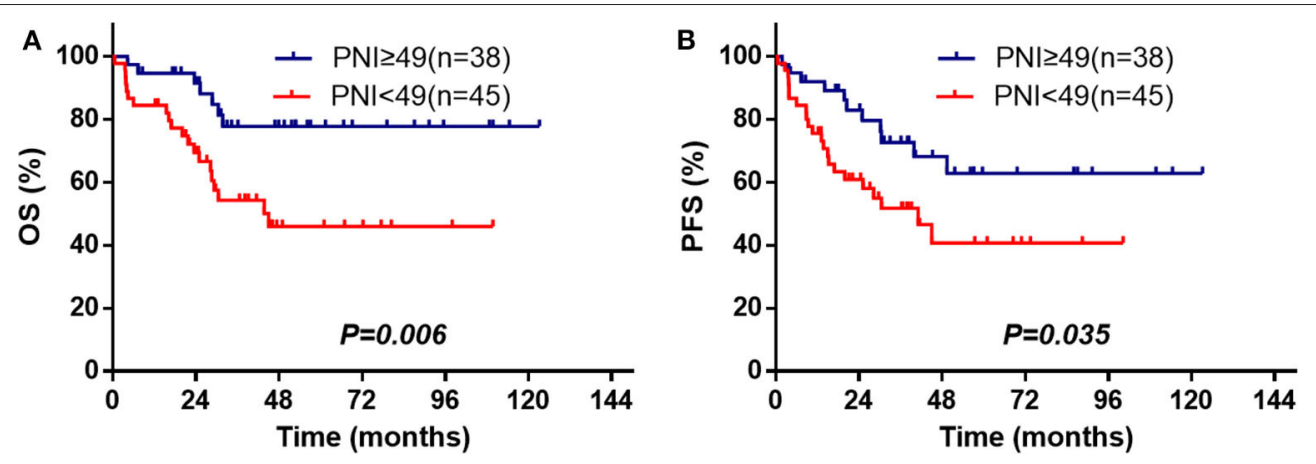

FIGURE 3 | PNI is associated with OS (A) and PFS (B) among the ENKTL patients treated with L-Asp-based chemotherapy.
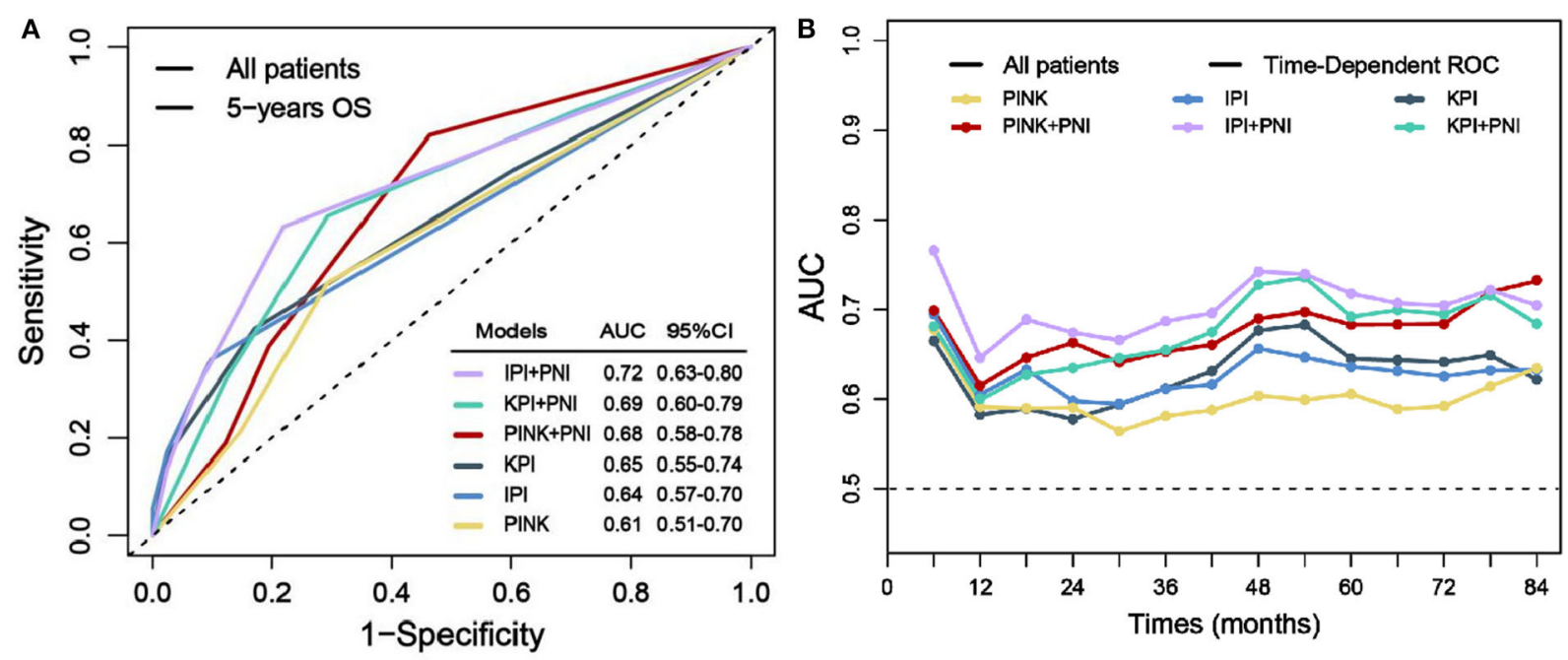

FIGURE 4 | Prognostic power evaluation of PNI. Before and after integrating PNI, AUC of the models in predicting 5-year OS (A) and the time-dependent AUC (B).

\section{DISCUSSION}

In this study, PNI related to the prognosis of ENKTL patients could be used to improve the performance of the frequently used models. Recently, PNI was identified as a prognostic marker for some malignancies; however, only the study from Gallamini et al. (25) was on ENKTL. Therefore, additional studies should be performed to verify the correlation between PNI and outcome of the patients. In this study, besides PNI, other valuable factors were also identified, such as ECOG score, LDH level, radiotherapy, and L-Asp-based chemotherapy for the ENKTL patients. Among them, it was necessary to further explore the efficacy of L-Asp-based chemotherapy.

In this study, PNI related to the prognosis of ENKTL patients could be used to improve the performance of the frequently used models. Recently, PNI was identified as a prognostic marker for some malignancies; however, only the study from Chen et al. (31) was on ENKTL. Therefore, additional studies should be performed to verify the correlation between PNI and outcome of the patients. In this study, besides PNI, other valuable factors were also identified, such as ECOG score, LDH level, radiotherapy, and L-Asp-based chemotherapy for the ENKTL patients. Among them, it was necessary to further explore the efficacy of L-Asp-based chemotherapy.

The cutoff value of PNI was usually estimated by the receiver operating characteristic curves (ROC) and was between 40 and 50 in previous studies $(19,21,32,33)$. However, if the censored observations that are ignored by the ROC method could be followed long enough, they would be eligible for the analysis (34). Therefore, to determine the optimal cutoff value of this cohort, we referred the method from Contal and O'Quigley (28) to include the potentially eligible cases.

Since ENKTL was a rare lymphatic disease, an external validation cohort was not easy to seek. We used the crossvalidation method as a substitution, and our results indicated that PNI was a credible and powerful prognostic factor.

The efficacy of traditional chemotherapy, such as CHOP or CHOP-like regimens, was not so satisfactory for the treatment of ENKTL patients and local relapse frequently occurred (35, 36). Therefore, it is necessary to develop new and effective drugs. The L-Asp-based chemotherapy regimens were proposed for refractory and relapsed diseases, and a complete response 
(CR) rate of $55.6 \%$ was achieved (37). Additionally, a metaanalysis suggested that the L-Asp-based regimen could improve overall response rate (ORR) and $\mathrm{CR}$ for both localized and systemic ENKTL (38). In accordance with previous reports, our study showed that the L-Asp-based chemotherapy was significant against OS in multivariate Cox regression. Furthermore, among the patients who received L-Asp-based chemotherapy, PNI was still associated with both OS and PFS. Therefore, these results indicated the prognostic ability of PNI.

The Ann Arbor staging system, originally designed for Hodgkin's lymphoma, is conventionally used for predicting the prognosis of ENKTL and is debated for its applicable value. A study indicated no significant differences between early-stage and advanced diseases in the complete remission rate or in survival rates (39). Additionally, China and Asia Lymphoma Study Group reported that the survival of stage IV patients was even better than those in stage III (40). These results coincided with ours and might be explained by the highly unbalanced distribution that stage I/II patients occupied almost $80 \%$ of newly diagnosed cases $(41,42)$.

Currently, many prognostic models, including the frequently used IPI, KPI, and PINK, have been proposed for ENKTL. However, these models have some more or less flaws and shortcomings. The patients were predominantly young in earlystage disease and good performance status and were in the lowrisk groups (0-1) according to the IPI or KPI classification. Therefore, in 2016, the PINK score was proposed as a new prognostic model; however, it was not so powerful in some cohorts $(43,44)$. Similarly, our results indicated that PINK was even inferior to IPI or KPI, and integrating PNI into the models could improve their predictive ability. Above all, PNI was an effective prognostic factor for ENKTL patients and might have a promising application in the future.

\section{CONCLUSION}

PNI is an effective prognostic factor for ENKTL patients with extranodal natural killer/T cell lymphoma, nasal type.

\section{REFERENCES}

1. Kanavaros P, Lescs MC, Briere J, Divine M, Galateau F, Joab I, et al. Nasal T-cell lymphoma: a clinicopathologic entity associated with peculiar phenotype and with Epstein-Barr virus. Blood. (1993) 81:2688-95. doi: 10.1182/blood.V81.10.2688.bloodjournal81102688

2. Jaccard A, Hermine O. Extranodal natural killer/T-cell lymphoma: advances in the management. Curr Opin Oncol. (2011) 23:429-35. doi: 10.1097/CCO.0b013e328349aba6

3. Kim SJ, Yang DH, Kim JS, Kwak JY, Eom HS, Hong DS, et al. Concurrent chemoradiotherapy followed by L-asparaginase-containing chemotherapy, VIDL, for localized nasal extranodal NK/T cell lymphoma: CISL08-01 phase II study. Ann Hematol. (2014) 93:1895-901. doi: 10.1007/s00277-014-2137-6

4. Yahalom J, Illidge T, Specht L, Hoppe RT, Li YX, Tsang R, et al. Modern radiation therapy for extranodal lymphomas: field and dose guidelines from the International Lymphoma Radiation Oncology Group. Int J Radiat Oncol Biol Phys. (2015) 92:11-31. doi: 10.1016/j.ijrobp.2015.01.009

5. Lee J, Suh C, Park YH, Ko YH, Bang SM, Lee JH, et al. Extranodal natural killer T-cell lymphoma, nasal-type: a prognostic model from a retrospective

\section{DATA AVAILABILITY STATEMENT}

The datasets generated for this study are available on request to the corresponding author.

\section{ETHICS STATEMENT}

The studies involving human participants were reviewed and approved by the Ethics Committee of Shanxi Provincial Cancer Hospital (the ethics number is 2019091). Written informed consent for participants was not required for this study in accordance with the national legislation and the institutional requirements.

\section{AUTHOR CONTRIBUTIONS}

JC and HS: research design and guidance, data acquisition, analysis and evaluation of statistical results, critical revision of the manuscript, and study supervision. NY, QH, SZ, and HX: data acquisition, study concept and design, analysis and interpretation of data, statistical analysis, and drafting of the manuscript. XX, YL, and RG: data acquisition, statistical analysis, organizing of data and tables, and reference surveys. HL and SL: critical revision of the manuscript and approved final submission.

\section{FUNDING}

This work was supported by the Key Research and Development (R\&D) Projects of Shanxi Province (no. 201803D31174) and the Fund Program for the Scientific Activities of Selected Returned Overseas Professionals in Shanxi Province.

\section{SUPPLEMENTARY MATERIAL}

The Supplementary Material for this article can be found online at: https://www.frontiersin.org/articles/10.3389/fonc. 2020.00877/full\#supplementary-material

multicenter study. J Clin Oncol. (2006) 24:612-8. doi: 10.1200/JCO.2005 04.1384

6. Chim CS, Ma SY, Au WY, Choy C, Lie AK, Liang R, et al. Primary nasal natural killer cell lymphoma: long-term treatment outcome and relationship with the International Prognostic Index. Blood. (2004) 103:21621. doi: 10.1182/blood-2003-05-1401

7. Yang Y, Cao JZ, Lan SM, Wu JX, Wu T, Zhu SY, et al. Association of improved locoregional control with prolonged survival in early-stage extranodal nasal-type natural killer/T-cell lymphoma. JAMA Oncol. (2017) 3:83-91. doi: 10.1001/jamaoncol. 2016.5094

8. Kim SJ, Kim BS, Choi CW, Choi J, Kim I, Lee YH, et al. Ki67 expression is predictive of prognosis in patients with stage I/II extranodal NK/T-cell lymphoma, nasal type. Ann Oncol. (2007) 18:1382-7. doi: 10.1093/annonc/mdm183

9. Huang JJ, Jiang WQ, Lin TY, Huang Y, Xu RH, Huang HQ, et al. Absolute lymphocyte count is a novel prognostic indicator in extranodal natural killer/T-cell lymphoma, nasal type. Ann Oncol. (2011) 22:149-55. doi: 10.1093/annonc/mdq314 
10. Huang JJ, Li YJ, Xia Y, Wang Y, Wei WX, Zhu YJ, et al. Prognostic significance of peripheral monocyte count in patients with extranodal natural killer/T-cell lymphoma. BMC Cancer. (2013) 13:222. doi: 10.1186/1471-2407-13-222

11. Yang Y, Zhang YJ, Zhu Y, Cao JZ, Yuan ZY, Xu LM, et al. Prognostic nomogram for overall survival in previously untreated patients with extranodal NK/T-cell lymphoma, nasal-type: a multicenter study. Leukemia. (2015) 29:1571-7. doi: 10.1038/leu.2015.44

12. Yang Y, Zhu Y, Cao JZ, Zhang YJ, Xu LM, Yuan ZY, et al. Riskadapted therapy for early-stage extranodal nasal-type NK/T-cell lymphoma: analysis from a multicenter study. Blood. (2015) 126:1424-32; quiz 517. doi: 10.1182/blood-2015-04-639336

13. Cao J, Lan S, Shen L, Si H, Xiao H, Yuan Q, et al. Hemoglobin level, a prognostic factor for nasal extranodal natural killer/T-cell lymphoma patients from stage I to IV: a validated prognostic nomogram. Sci Rep. (2017) 7:10982. doi: 10.1038/s41598-017-11137-9

14. McMillan DC. Systemic inflammation, nutritional status and survival in patients with cancer. Curr Opin Clin Nutr Metab Care. (2009) 12:223-6. doi: 10.1097/MCO.0b013e32832a7902

15. Sidaway P. Platelet-to-lymphocyte ratio predicts prostate cancer prognosis. Nat Rev Urol. (2015) 12:238. doi: 10.1038/nrurol.2015.69

16. Krenn-Pilko S, Langsenlehner U, Thurner EM, Stojakovic T, Pichler M, Gerger A, et al. The elevated preoperative platelet-to-lymphocyte ratio predicts poor prognosis in breast cancer patients. Br J Cancer. (2014) 110:2524-30. doi: $10.1038 /$ bjc. 2014.163

17. Kinoshita A, Onoda H, Imai N, Iwaku A, Oishi M, Tanaka K, et al. The Creactive protein/albumin ratio, a novel inflammation-based prognostic score, predicts outcomes in patients with hepatocellular carcinoma. Ann Surg Oncol. (2015) 22:803-10. doi: 10.1245/s10434-014-4048-0

18. Coussens LM, Werb Z. Inflammation and cancer. Nature. (2002) 420:860-7. doi: 10.1038/nature01322

19. Perisa V, Zibar L, Knezovic A, Perisa I, Sincic-Petricevic J, Aurer I. Prognostic nutritional index as a predictor of prognosis in patients with diffuse large B cell lymphoma. Wien Klin Wochenschr. (2017) 129:411-9. doi: $10.1007 / \mathrm{s} 00508-016-1077-7$

20. Go SI, Park S, Kang MH, Kim HG, Kim HR, Lee GW. Clinical impact of prognostic nutritional index in diffuse large B cell lymphoma. Ann Hematol. (2019) 98:401-11. doi: 10.1007/s00277-018-3540-1

21. Lee SF, Ng TY, Wong FCS. The value of prognostic nutritional index in follicular lymphoma. Am J Clin Oncol. (2019) 42:202-7. doi: 10.1097/COC.0000000000000493

22. Kim TM, Heo DS. Extranodal NK/T-cell lymphoma, nasal type: new staging system and treatment strategies. Cancer Sci. (2009) 100:2242-8. doi: 10.1111/j.1349-7006.2009.01319.x

23. Qi SN, Xu LM, Yuan ZY, Wu T, Zhu SY, Shi M, et al. Effect of primary tumor invasion on treatment and survival in extranodal nasal-type NK/Tcell lymphoma in the modern chemotherapy era: a multicenter study from the China Lymphoma Collaborative Group (CLCG). Leuk Lymphoma. (2019) 60:2669-78. doi: 10.1080/10428194.2019.1602265

24. International Non-Hodgkin's Lymphoma Prognostic Factors Project. A predictive model for aggressive non-Hodgkin's lymphoma. $N$ Engl J Med. (1993) 329:987-94. doi: 10.1056/NEJM199309303291402

25. Gallamini A, Stelitano C, Calvi R, Bellei M, Mattei D, Vitolo U, et al. Peripheral T-cell lymphoma unspecified (PTCL-U): a new prognostic model from a retrospective multicentric clinical study. Blood. (2004) 103:2474-9. doi: 10.1182/blood-2003-09-3080

26. Kim SJ, Yoon DH, Jaccard A, Chng WJ, Lim ST, Hong H, et al. A prognostic index for natural killer cell lymphoma after non-anthracyclinebased treatment: a multicentre, retrospective analysis. Lancet Oncol. (2016) 17:389-400. doi: 10.1016/S1470-2045(15)00533-1

27. Onodera T, Goseki N, Kosaki G. Prognostic nutritional index in gastrointestinal surgery of malnourished cancer patients. Nihon Geka Gakkai Zasshi. (1984) 85:1001-5.

28. Contal C, O'Quigley J. An application of changepoint methods in studying the effect of age on survival in breast cancer. Comput Stat Data Anal. (1999) 30:253-70. doi: 10.1016/S0167-9473(98)00096-6

29. Ho DE, Imai K, King G, Stuart EA. Matching as nonparametric preprocessing for reducing model dependence in parametric causal inference. Polit Anal. (2017) 15:199-236. doi: 10.1093/pan/mpl013
30. Simon N, Friedman J, Hastie T, Tibshirani R. Regularization paths for cox's proportional hazards model via coordinate descent. J Stat Softw. (2011) 39:1-13. doi: 10.18637/jss.v039.i05

31. Chen KL, Liu YH, Li WY, Chen J, Gu YK, Geng QR, et al. The prognostic nutritional index predicts survival for patients with extranodal natural killer/T cell lymphoma, nasal type. Ann Hematol. (2015) 94:1389-400. doi: $10.1007 / \mathrm{s} 00277-015-2361-8$

32. Shoji F, Morodomi Y, Akamine T, Takamori S, Katsura M, Takada K, et al. Predictive impact for postoperative recurrence using the preoperative prognostic nutritional index in pathological stage I non-small cell lung cancer. Lung Cancer. (2016) 98:15-21. doi: 10.1016/j.lungcan.2016.05.010

33. Kanda M, Mizuno A, Tanaka C, Kobayashi D, Fujiwara M, Iwata N, et al. Nutritional predictors for postoperative short-term and long-term outcomes of patients with gastric cancer. Medicine (Baltimore). (2016) 95:e3781. doi: 10.1097/MD.0000000000003781

34. Steyerberg EW, Vickers AJ, Cook NR, Gerds T, Gonen M, Obuchowski $\mathrm{N}$, et al. Assessing the performance of prediction models: a framework for traditional and novel measures. Epidemiology. (2010) 21:128-38. doi: 10.1097/EDE.0b013e3181c30fb2

35. Li C-C, Tien H-F, Tang J-L, Yao M, Chen Y-C, Su I-J, et al. Treatment outcome and pattern of failure in 77 patients with sinonasal natural killer/T-cell or T-cell lymphoma. Cancer. (2004) 100:366-75. doi: 10.1002/cncr.11908

36. Au Wy, Weisenburger DD, Intragumtornchai $\mathrm{T}$, Nakamura $\mathrm{S}$, Kim WS, Sng I, et al. Clinical differences between nasal and extranasal natural killer/T-cell lymphoma: a study of 136 cases from the International Peripheral T-Cell Lymphoma Project. Blood. (2008) 113:3931-7. doi: 10.1182/blood-2008-10-185256

37. Yong $\mathrm{W}$, Zheng $\mathrm{W}$, Zhu J, Zhang Y, Wang X, Xie Y, et al. L-asparaginase in the treatment of refractory and relapsed extranodal NK/T-cell lymphoma, nasal type. Ann Hematol. (2009) 88:647-52. doi: 10.1007/s00277-008-0669-3

38. Pokrovsky VS, Vinnikov D. L-Asparaginase for newly diagnosed extranodal NK/T-cell lymphoma: systematic review and meta-analysis. Expert Rev Anticancer Ther. (2017) 17:759-68. doi: 10.1080/14737140.2017.1344100

39. Pagano L, Gallamini A, Trape G, Fianchi L, Mattei D, Todeschini G, et al. NK/T-cell lymphomas 'nasal type': an Italian multicentric retrospective survey. Ann Oncol. (2006) 17:794-800. doi: 10.1093/annonc/mdl015

40. Hong H, Li Y, Lim ST, Liang C, Huang H, Yi P, et al. A proposal for a new staging system for extranodal natural killer T-cell lymphoma: a multicenter study from China and Asia Lymphoma Study Group. Leukemia. (2020). doi: 10.1038/s41375-020-0740-1. [Epub ahead of print].

41. Greer JP, Mosse CA. Natural killer-cell neoplasms. Curr Hematol Malig Rep. (2009) 4:245-52. doi: 10.1007/s11899-009-0032-3

42. Suzuki R, Suzumiya J, Yamaguchi M, Nakamura S, Kameoka J, Kojima H, et al. Prognostic factors for mature natural killer (NK) cell neoplasms: aggressive NK cell leukemia and extranodal NK cell lymphoma, nasal type. Ann Oncol. (2010) 21:1032-40. doi: 10.1093/annonc/mdp418

43. Yamaguchi $M$, Tobinai $K$, Oguchi $M$, Ishizuka $N$, Kobayashi $Y$, Isobe $\mathrm{Y}$, et al. Phase I/II study of concurrent chemoradiotherapy for localized nasal natural killer/T-cell lymphoma: Japan Clinical Oncology Group Study JCOG0211. J Clin Oncol. (2009) 27:5594-600. doi: 10.1200/JCO.2009. 23.8295

44. Yamaguchi M, Suzuki R, Oguchi M, Asano N, Amaki J, Akiba T, et al. Treatments and outcomes of patients with extranodal natural killer/T-cell lymphoma diagnosed between 2000 and 2013: a cooperative study in Japan. J Clin Oncol. (2017) 35:32-9. doi: 10.1200/JCO.2016. 68.1619

Conflict of Interest: The authors declare that the research was conducted in the absence of any commercial or financial relationships that could be construed as a potential conflict of interest.

Copyright (๑) 2020 Yao, Hou, Zhang, Xiao, Liang, Xu, Guo, Li, Lan, Si and Cao. This is an open-access article distributed under the terms of the Creative Commons Attribution License (CC BY). The use, distribution or reproduction in other forums is permitted, provided the original author(s) and the copyright owner(s) are credited and that the original publication in this journal is cited, in accordance with accepted academic practice. No use, distribution or reproduction is permitted which does not comply with these terms. 